\title{
Chemoembolization of unresectable hepatocellular carcinoma: Decreased toxicity with slow-release doxorubicin-eluting beads compared with lipiodol
}

\author{
FRANCESCO RECCHIA ${ }^{1,2}$, GIOVANNI PASSALACQUA ${ }^{3}$, PIETRO FILAURI $^{3}$, MARCO DODDI $^{3}$, \\ PIETRO BOSCARATO ${ }^{3}$, GIAMPIERO CANDELORO ${ }^{1}$, STEFANO NECOZIONE ${ }^{4}$, \\ GIOVAMBATTISTA DESIDERI ${ }^{4}$ and SILVIO REA ${ }^{2,5}$ \\ ${ }^{1}$ Department of Oncology, Civilian Hospital, Avezzano; ${ }^{2}$ Carlo Ferri Foundation, Monterotondo, Rome; \\ ${ }^{3}$ Department of Interventional Radiology, Civilian Hospital, Avezzano; Departments of ${ }^{4}$ Internal Medicine \\ and Public Health and ${ }^{5}$ Experimental Medicine, University of L'Aquila, L'Aquila, Italy
}

Received November 10, 2011; Accepted December 29, 2011

DOI: $10.3892 /$ or.2012.1651

\begin{abstract}
Chemoembolization with lipiodol (TACE) improves survival of selected patients with unresectable hepatocellular carcinoma (HCC), but results in substantial toxicity. To improve treatment tolerance, we conducted this phase II study using doxorubicin-loaded beads (DC Beads ${ }^{\circledR}$ ) delivered by selective transcatheter arterial chemoembolization (DEB-TACE). We compared the results with those obtained with TACE in our historical controls. Thirty-five patients were recruited with diagnoses of HCC. Patients received DEB-TACE with doxorubicin loaded on DC Beads. Computed tomography of the upper abdomen was performed one month after DEB-TACE. Historical controls were a group of 70 patients with matched characteristics treated with TACE. After a median follow-up of 14.1 months (range, 6-36 months), 22 patients (63\%) had an objective response. There was a statistically significant decrease in liver enzymes $(\mathrm{P}<0.001)$, lactate dehydrogenase, $(\mathrm{P}<0.001)$ in DEB-TACE-treated patients compared to TACE-treated patients. DEB-TACE with doxorubicin-loaded DC Beads, a safe and reliable treatment for HCC, leads to decreased toxicity compared to TACE.
\end{abstract}

\section{Introduction}

Hepatocellular carcinoma (HCC), the fifth most common neoplasm and the third most common cause of cancer-related death, is an important health problem, with more than half a million new cases registered annually worldwide (1). Application of screening programs, advances in diagnostic imaging, and the increasing incidence of hepatitis $\mathrm{C}$ virus underlie the increasing

Correspondence to: Dr Francesco Recchia, Department of Oncology, Strada del Castagneto 15, 67056 Luco dei Marsi (AQ), Italy

E-mail: frecchia1946@libero.it

Key words: chemoembolization, DC Beads, lipiodol incidence of HCC in Western countries and Japan (2). The HCC that develops in $80-90 \%$ of cases of cirrhotic liver is the main cause of death among cirrhotic patients (2).

The best therapeutic results occur after liver transplantation with resection of the entire potentially tumor-bearing liver and elimination of cirrhosis. However, transplantation can be offered only to a minority of patients due to the shortage of donors and the high cost of the procedure (3). Most patients are not amenable to potentially curative partial hepatectomy because the tumor is in an advanced stage and liver function is poor at the time of diagnosis (4). For this reason, various locoregional therapies are used for patients who are not surgical candidates as a result of the severity of the liver disease or advanced HCC stage. These modalities include local ablative therapy (radiofrequency ablation, microwave coagulation therapy, or percutaneous ethanol injection) and transarterial chemoembolization with lipiodol (TACE). In HCC, the hepatic artery provides $90-100 \%$ of the blood supply to the tumor and is used as a roadway for direct delivery of therapeutic agents to the tumor while the non-neoplastic liver is not damaged (4).

TACE has become the most popular modality for palliative treatment among non-surgical candidates. Two randomized trials from Europe and Asia confirmed better survival associated with TACE vs. conservative treatment in selected patients $(5,6)$. In recent years, TACE with an emulsion of doxorubicin with lipiodol followed by embolization with a gelatin sponge has been used commonly for HCC treatment $(7,8)$; however, the treated tumors exhibited a high frequency of recurrence after TACE (9-11). In addition, the most common complication of TACE is the post-embolization syndrome, which consists of fever, abdominal pain, nausea, vomiting, leukocytosis, and increased liver enzymes lasting from a few hours to a few days (10). The post-embolization syndrome has widely variable manifestations, is experienced after $80-90 \%$ of TACE procedures, is treated symptomatically and, in most patients, decreases in severity with subsequent TACE but may prolong hospitalization (11). The chemotherapeutic and embolizing agents may also cause acute cholecystitis, biliary tract necrosis, pancreatitis, gastric erosions, or ulcers if they are inadvertently 
injected into these organs. Infection of the necrotic tumor presenting as liver abscess can also occur (10).

Recently, microspheres (DC Beads ${ }^{\circledR}$, Biocompatibles UK, Ltd., Surrey, UK) that can be labeled with antineoplastic drugs, delivered by selective transcatheter arterial chemoembolization (DEB-TACE), have been utilized for the treatment of HCC $(12,13)$. These particles provide two major advantages over conventional TACE. First, the drug attached to the particles is released to the surrounding tissue continuously during the first 10-12 days. Second, due to the sustained drug release, the plasma levels of the charged drug are supposed to be lower than in conventional TACE, resulting in fewer systemic side effects (13).

The primary endpoint of the present study was to prospectively assess the toxicity of DEB-TACE in a cohort of 35 patients with unresectable $\mathrm{HCC}$ and to compare it with the toxicity of TACE in 70 matched historical controls with comparable disease stage and age. The secondary endpoint was the assessment of DEB-TACE activity.

\section{Materials and methods}

Patient selection. Patients with a diagnosis of HCC who had no indication for surgical resection or local ablation therapy were enrolled in the present prospective case-control study. Inclusion criteria, that were common for the prospectively included patients and for the controls, included: age $<80$ years, adequate liver function, Karnofsky performance score $>70 \%$, no serious associated medical illness, no extrahepatic disease on preoperative investigations, no major vessel involvement by tumor including the main portal vein, main hepatic artery, hepatic veins or inferior vena cava.

HCC was diagnosed by ultrasonography, computed tomography $(\mathrm{CT})$, magnetic resonance imaging, angiography, and the measurement of serum levels of $\alpha$-fetoprotein (AFP). A combination of AFP and imaging was used in 12 patients for whom histological examination was not performed.

Liver-function criteria for enrollment included Child A or B class, bilirubin $<3 \mathrm{mg} / \mathrm{dl}$, and aspartate aminotransferase (AST) and alanine aminotransferase (ALT) <270 IU/1. None of the patients were candidates for liver transplantation. Patients with creatinine $>2 \mathrm{mg} / \mathrm{dl}$, port systemic shunts, hepatofugal blood flow, thrombosis of the main portal vein, extrahepatic metastases, and tumor burden ( $>50 \%$ of the liver volume) were excluded. Tumor stage was estimated by the OkudaChild classification (14). Informed consent was obtained from all patients. This study protocol was approved by the local Ethics Committee and was conducted in accordance with the Declaration of Helsinki.

Drug-eluting microspheres/beads. The DEB-TACE procedure was performed with local analgesia, antibiotic prophylaxis, and antiemetic drugs. Particular attention was paid to postembolization pain control with a combination of opioids and fans. Patients received DEB-TACE via DC Beads loaded with doxorubicin at a dose of $50 \mathrm{mg} / \mathrm{m}^{2}$ (15). The microspheres were left in solution with doxorubicin over $2 \mathrm{~h}$. Microsphere size was chosen according to the tumor size. For tumors $>5 \mathrm{~cm}$ the size was between 500 and $700 \mu \mathrm{m}$, for tumors between 5 and $3 \mathrm{~cm}$, the size was $300-500 \mu \mathrm{m}$, while for tumors $<3 \mathrm{~cm}$ the size was
$300 \mu \mathrm{m}$. Prior to each embolization, angiography of the hepatic and mesenteric arteries was performed to demonstrate liver arterial anatomy and the feeding vessels of the tumor and to check for apparent venous shunts. DC Beads were then aspirated from the vial into a syringe and mixed with saline solution and non-ionic contrast medium (300-400 $\mathrm{mg} / \mathrm{ml}$ iodine). Once the catheter was in place in the artery feeding the tumor, the DC Beads were infused selectively into the vessel until stasis was evident. Lobar or segmental embolization was performed in the case of diffuse tumors. If hepatic vein shunting was identified angiographically, larger particles or preliminary shunt embolization were implemented to minimize the risk of non-target pulmonary embolization.

Follow-up. CT and contrast-enhanced ultrasound were used to assess results, while magnetic resonance imaging was used only to search for satellite lesions or new tumors that would modify the clinical decision. CT consisted of three phases performed on a spiral CT scanner. The scans were obtained through the liver in the craniocaudal direction with $5-\mathrm{mm}$ collimation. For the three-phase CT, the hepatic arterial, portal venous, and delayed phases were scanned at 30,60 and $180 \mathrm{sec}$, respectively, after the start of the injection of $120 \mathrm{ml}$ of non-ionic iodinated contrast material. Magnetic resonance imaging included T1 fat-suppressed images, T2 fat-suppressed sequences and dynamic fat-suppressed T1 sequences with gadolinium enhancement.

Modified response evaluation criteria in solid tumors (RECIST) criteria were used to evaluate responses to treatment (16). Imaging follow-up was scheduled at baseline (before the procedure) and 1 month after each treatment. Follow-up was performed 4, 7 and 9 months after procedures.

In each imaging evaluation the longest diameter of the tumor, the longest diameter of the enhancing/viable tumor, and the percentage of necrosis post-treatment were recorded. Necrosis was defined as a non-enhancing and low-fluid density intratumoral area.

Patients were evaluated for toxicity at each study visit according to the National Cancer Institute Common Toxicity Criteria (NCI-CTC) Version 2.0.11. AFP levels were measured at follow-up, while ALT, AST and lactate dehydrogenase (LDH) levels were measured before and daily after the procedure.

Statistical analysis. The primary objective of the study was to determine whether DEB-TACE with DC Beads produced a decrease in toxicity vs. TACE with lipiodol. The number of patients required to identify a statistically significant $(\mathrm{P} \leq 0.05)$ decrease of $\geq 25 \%$ in the post-embolization AST value was calculated to be 35 subjects in the experimental group and 70 subjects in the control group providing a statistical power $>90 \%$. The results of the laboratory tests were expressed as the mean \pm standard deviation of four determinations, and the differences were determined using a repeated-measure analysis of variance. Secondary endpoints were response, relapse-free survival (RFS) and overall survival (OS). The RFS was defined as the time between the embolization to any relapse and the appearance of a second primary cancer or death, whichever occurred first. The OS was measured from study entry to death, or June 30, 2011 for censored patients. RFS and 
Table I. Patient characteristics of the experimental group and historical controls.

\begin{tabular}{|c|c|c|}
\hline & $\begin{array}{c}\text { Study patients } \\
\text { n }(\%)\end{array}$ & $\begin{array}{c}\text { Controls } \\
\mathrm{n}(\%)\end{array}$ \\
\hline No. of patients & $35(100)$ & $70(100)$ \\
\hline \multicolumn{3}{|l|}{ Gender } \\
\hline Male & $25(71)$ & $50(71)$ \\
\hline Female & $10(29)$ & $20(29)$ \\
\hline \multicolumn{3}{|l|}{ Age (years) } \\
\hline Median & 72 & 70 \\
\hline Range & $53-80$ & $47-80$ \\
\hline \multicolumn{3}{|c|}{ Number of lesions } \\
\hline Total & 54 & 112 \\
\hline Range & $1-3$ & $1-3$ \\
\hline \multicolumn{3}{|l|}{ Diameter $(\mathrm{cm})$} \\
\hline Median & 4.12 & 5.3 \\
\hline Range & $1-9$ & $2-9$ \\
\hline \multicolumn{3}{|c|}{ Stage (Okuda-Child) } \\
\hline $1 \mathrm{~A}$ & $6(17)$ & $9(13)$ \\
\hline 1B & $8(23)$ & $15(21)$ \\
\hline $2 \mathrm{~A}$ & $6(17)$ & $19(27)$ \\
\hline $2 \mathrm{~B}$ & $15(43)$ & $27(39)$ \\
\hline
\end{tabular}

OS were calculated using the Kaplan-Meier method (17). All comparisons were performed using Pearson's $\chi^{2}$ contingency table analysis. The log-rank test was used to compare the RFS and OS of the two groups. Statistical analysis was performed with SAS statistical software (version 8.12,2000; SAS Institute Inc., Cary, NC, USA).

\section{Results}

Patient characteristics. Between January 2008 and December 2010, 35 patients were recruited (25 males and 10 females) with a median age of 72 years (range, 53-80 years). All patients had Eastern Cooperative Oncology Group (ECOG) performance status 0-1. The total number of lesions was 54 (range, 1-3 per patient) with a median diameter of $4.12 \mathrm{~cm}$ (range, 1-9 $\mathrm{cm})$. Okuda-Child stages were determined to be $1 \mathrm{~A}(\mathrm{n}=6), 1 \mathrm{~B}$ $(\mathrm{n}=8), 2 \mathrm{~A}(\mathrm{n}=6)$ and 2B $(\mathrm{n}=15)$ (Table I).

The control patients $(n=70)$ possessed similar characteristics regarding age, disease status, performance status, and number of hepatic lesions (Table I).

Tumor response and patient survival. After a median follow-up of 14.1 months (range, 6-40 months), a total of 61 DEB-TACEs were delivered (range, 1-4 treatments per patient). According to the modified RECIST criteria, an objective overall response rate was observed in 22 patients (63\%): complete response in 7 patients (20\%), partial response in 15 patients (43\%), stable disease in 9 patients (26\%), and progressive disease in 4 patients (11\%; Table II). Seven partial responses were converted to complete responses after a second treatment,

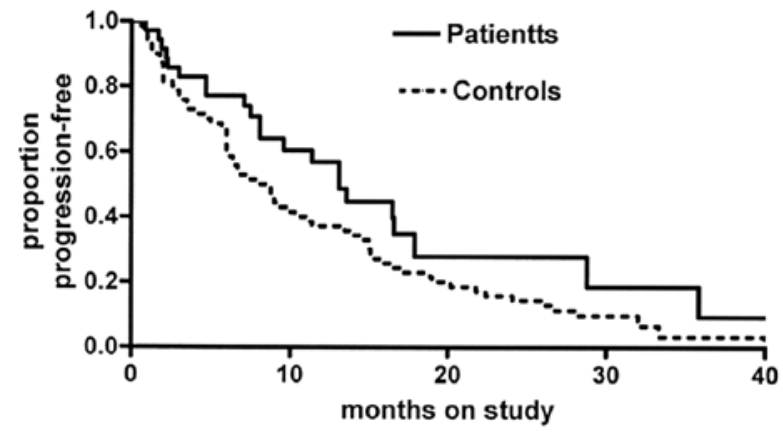

Figure 1. Relapse-free survival (RFS). There was no statistically significant difference in RFS between the chemoembolization with lipiodol (TACE) (median 8.4 months) and embolization with doxorubicin-loaded beads (DEB-TACE) (median 13.1 months).

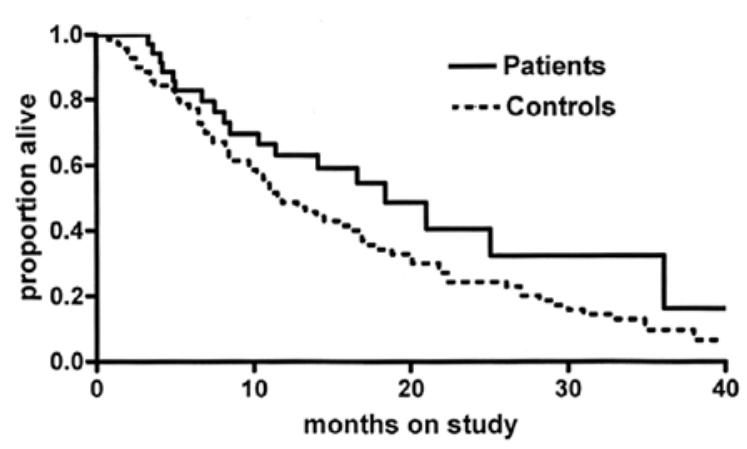

Figure 2. Overall survival (OS). There was no statistically significant difference in OS between the chemoembolization with lipiodol (TACE) (median 11.4 months) and embolization with doxorubicin-loaded beads (DEB-TACE) (median 18.4 months).

while five stable diseases were converted to partial responses (Table II). The median RFS was 13.1 months (range, 1-36+ months), while the median OS was 18.4 months. Two patients remained in complete response at the time of death caused by liver failure. Eleven patients (31\%) were alive at the time of analysis with a significant $(\mathrm{P}<0.05)$ decrease of AFP level with respect to pretreatment values. Nine percent of the historical controls were alive at the time of this analysis; their median RFS was 8.4 months while their median OS was 11.4 months. There was no statistically significant difference in RFS or OS between the two groups of patients (Figs. 1 and 2).

Toxicity. Table III contains a summary of adverse effects in the two treatment groups. The incidence of nausea/vomiting in the TACE group was significantly higher than that in the DEB-TACE group $(\mathrm{P}<0.001)$. The median length of hospitalization was $4.7 \pm 0.7$ days for TACE and $2.3 \pm 0.1$ days for DEB-TACE $(\mathrm{P}<0.0001)$. Causes of hospitalization included fever and other treatment-related complications. Increases in the ALT and LDH levels were observed for 9 days and at 4 days for the TACE and DEB-TACE groups, respectively (data not shown). Mean baseline AST values did not statistically differ between groups: $109 \pm 12$ (IU) for the TACE group and $116 \pm 31$ for the DEB-TACE group. After the procedures the difference between the mean AST values became statistically significant ( $\mathrm{P}<0.05)$ : $805 \pm 125$ for TACE and $238 \pm 57$ for DEB-TACE (Fig. 3). Similar observations were obtained for LDH levels; 
Table II. Patient responses according to the RECIST criteria.

Patients, n (\%)

\begin{tabular}{lccc} 
Response & After first embolization & After second embolization & After third embolization \\
\hline Complete response (CR) & $7(20)$ & $7(43.75)$ & $3(50)$ \\
Partial response (PR) & $15(43)$ & $5(31.25)$ & $1(16.66)$ \\
Stable disease (SD) & $9(26)$ & $3(18.75)$ & $1(16.66)$ \\
Progressive disease (PD) & $4(11)$ & $1(6.25)$ & $0(0)$ \\
Total patients & $35(100)$ & $16(100)$ & $6(100)$ \\
Response rate (RR) & $22(63)$ & $12(75)$ & $4(66.66)$
\end{tabular}

RECIST, response evaluation criteria in solid tumors.

Table III. Patient toxicities.

\begin{tabular}{|c|c|c|c|c|c|c|}
\hline & \multicolumn{6}{|c|}{ NCI-CTC grade } \\
\hline & $\begin{array}{c}0 \\
\mathrm{n}(\%)\end{array}$ & $\begin{array}{c}1 \\
\mathrm{n}(\%)\end{array}$ & $\begin{array}{c}2 \\
\mathrm{n}(\%)\end{array}$ & $\begin{array}{c}3 \\
\mathrm{n}(\%)\end{array}$ & $\begin{array}{c}4 \\
\mathrm{n}(\%)\end{array}$ & $\begin{array}{l}\text { Total } \\
\mathrm{n}(\%)\end{array}$ \\
\hline \multicolumn{7}{|l|}{ Hematological } \\
\hline Leukopenia & $29(83)$ & $5(14)$ & $1(3)$ & $0(0)$ & $0(0)$ & $35(100)$ \\
\hline Neutropenia & $27(77)$ & $7(20)$ & $1(3)$ & $0(0)$ & $0(0)$ & $35(100)$ \\
\hline Thrombocytopenia & $33(94)$ & $2(6)$ & $0(0)$ & $0(0)$ & $0(0)$ & $35(100)$ \\
\hline Anemia & $31(89$ & $4(11)$ & $0(0)$ & $0(0)$ & $0(0)$ & $35(100)$ \\
\hline Infection & $25(71)$ & $0(0)$ & $9(26)$ & $1(3)$ & $0(0)$ & $35(100)$ \\
\hline Nausea and vomiting & $24(68)$ & $8(23)$ & $3(9)$ & $0(0)$ & $0(0)$ & $35(100)$ \\
\hline AST & $11(31)$ & $15(43)$ & $9(26)$ & $0(0)$ & $0(0)$ & $35(100)$ \\
\hline ALT & $16(46)$ & $13(37)$ & $6(17)$ & $0(0)$ & $0(0)$ & $35(100)$ \\
\hline Abdominal Pain & $1(3)$ & $19(54)$ & $8(23)$ & $7(20)$ & $0(0)$ & $35(100)$ \\
\hline Fever & $25(71)$ & $8(23)$ & $2(6)$ & $0(0)$ & $0(0)$ & $35(100)$ \\
\hline
\end{tabular}

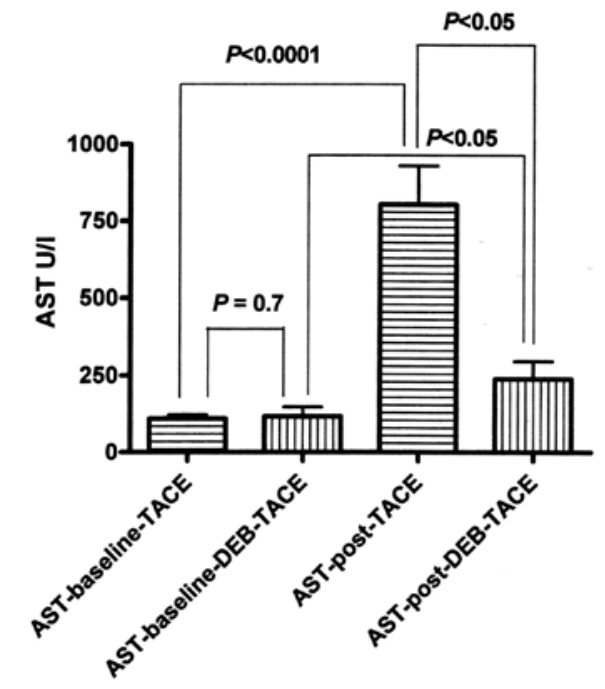

Figure 3. Alanine aminotransferase (AST) levels. There was no statistically significant difference in the baseline AST values between chemoembolization with lipiodol (TACE) and embolization with doxorubicin-loaded beads (DEB-TACE). After the procedures, the difference became statistically significant $(\mathrm{P}<0.0001$ and $\mathrm{P}<0.05$, respectively). A statistically significant difference was observed between AST levels in the two groups after the procedures $(\mathrm{P}<0.05)$.

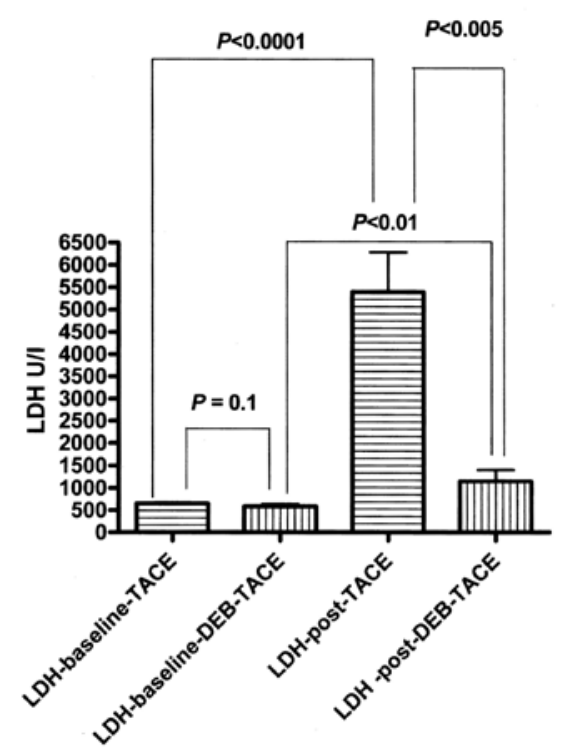

Figure 4. Lactate dehydrogenase (LDH) levels. There was no statistically significant difference between the baseline LDH values of the two treatment groups. After both procedures the difference became statistically significant $(\mathrm{P}<0.0001$ and $\mathrm{P}<0.05$, respectively). There was also a statistically significant difference in $\mathrm{LDH}$ values after the procedures $(\mathrm{P}<0.005)$. 

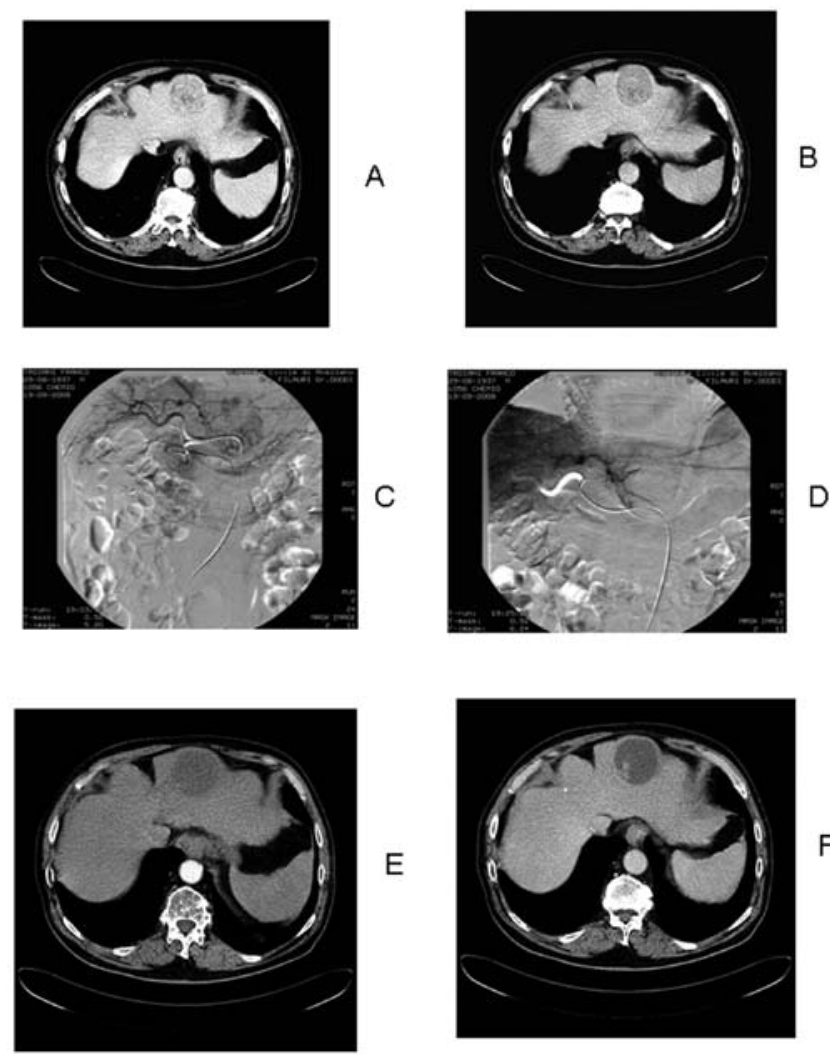

E

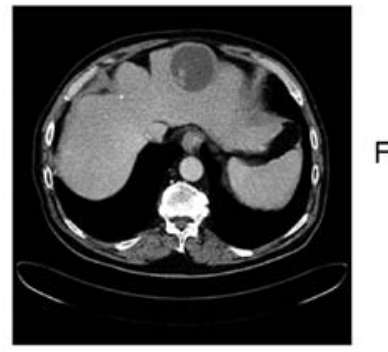

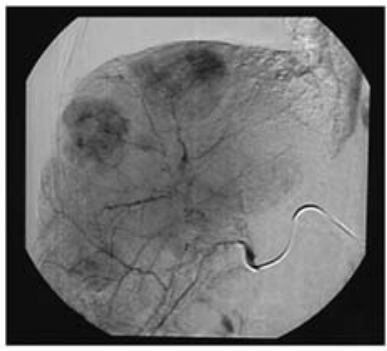

A

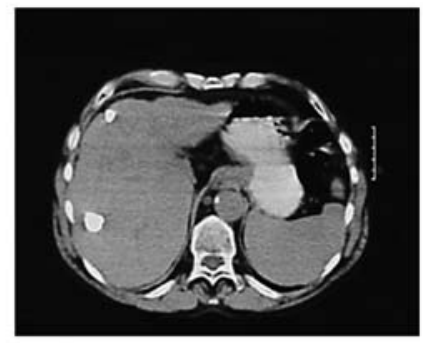

$\mathrm{B}$

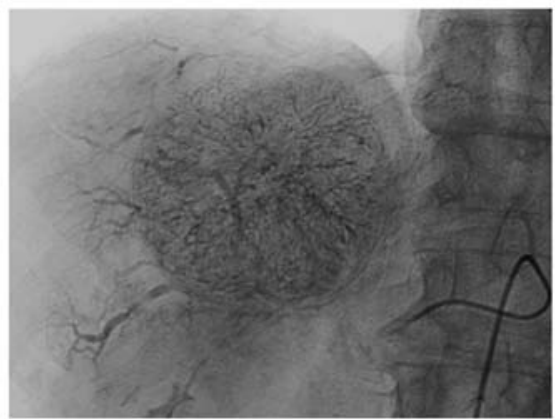

C

Figure 6. Lipiodol chemoembolization. (A) Diagnostic angiography with focal enhancement. Baseline post-treatment computed tomography (B) illustrating lipiodol focal concentration in the lesion. (C) Peculiar lipiodol distribution of the lesion.

Figure 5. Phases of embolization with doxorubicin-loaded beads (DEBTACE). Portal phase (A) and venous phase (B) of pre-treatment computed tomography (CT) of a hepatocellular carcinoma. Angiography of the same hepatic lesion before (C) and after (D) TACE. Post-treatment CT in the arterial phase $(\mathrm{E})$ and in the venous phase $(\mathrm{F})$ showing a partial response to TACE.

baseline $\mathrm{LDH}$ values were $652 \pm 24$ (IU) in the TACE group and $584 \pm 53$ in the DEB-TACE group $(\mathrm{P}<0.1)$, and after the procedures, the mean $\mathrm{LDH}$ value increased to $5399 \pm 800 \mathrm{IU}$ for the TACE group and $1153 \pm 251$ for the DEB-TACE group $(\mathrm{P}<0.005$; Fig. 4). No toxicity-related death was observed in the total pool of 105 patients treated with the two procedures. We observed hepatic artery damage in two patients treated with TACE and in no patients treated with DEB-TACE. No patient exhibited occlusion of the hepatic artery. No other serious complications or treatment-related deaths were observed in either group as shown in Figs. 5 and 6.

\section{Discussion}

Randomized trials have established that with respect to best supportive care, TACE prolongs the survival of a selected group of patients with unresectable HCC and is an effective palliative treatment $(18,19)$. In addition, a large meta-analysis clearly demonstrated that in patients with unresectable HCC, chemoembolization significantly improved the overall 2-year survival compared with non-active treatment (20).

Loading the drug doxorubicin onto microspheres represents a new modality for precise delivery; once the microspheres are injected into the tumor, they slowly release doxorubicin over 14 days, causing a prolonged, concentrated exposure to the drug, with increased cell death and decreased acute toxicity

(12). A recent study reported a significantly decreased toxicity of DEB-TACE due to significantly lower plasma doxorubicin concentration with DC Beads (21). Conventional TACE delivers drugs less selectively into liver lesions and causes damage to the surrounding liver tissue, with elevation of liver enzymes and acceleration of underlying liver disease (22). Following refinement of the technique with superselective angiography, the drug is now precisely delivered to the lesion, is released slowly, and has an improved impact on the surrounding liver parenchyma.

In another clinical study, the authors hypothesized that DEB-TACE presented a better local response, fewer recurrences, and a longer RFS, due to complete devascularization of the lesion, leading to reduced neoangiogenesis (23).

The aims of this case-control study were the evaluation of DEB-TACE toxicity, its activity in 35 patients with unresectable HCC and the comparison of these results with those obtained from a group of 70 TACE-treated controls with the same pathology. The historical controls were selected to have characteristics similar to our patients.

In our study, toxicity following DEB-TACE was significantly decreased with respect to lipiodol chemoembolization. The length of hospital stay decreased from a mean of 5 days to a mean of 3 days $(\mathrm{P}<0.001)$, and postoperative complications also decreased significantly. The lowered toxicity was also observed for AST and LDH. In fact even if there was no statistically significant difference between mean baseline values of both AST $(\mathrm{P}=0.7)$ and $\mathrm{LDH}(\mathrm{P}=0.1)$, after the procedure the difference became statistically significant for both AST $(\mathrm{P}<0.05)$ and LDH $(\mathrm{P}<0.005)$ (Figs. 3 and 4$)$.

Transcatheter therapy with DC Beads did not provide a statistically significant advantage in RFS (Fig. 1) or in OS 
(Fig. 2) with respect to TACE in patients with unresectable HCC. However, few patients received a large benefit from either procedure. Prolonging the life expectancy of these patients led to the observation of unusual metastasis sites; two patients in each group developed several bone metastases three years after the procedure, while two other patients in each group died from brain metastases.

Several limitations of our study deserve discussion. Although our investigation was not a randomized study, our controls were carefully selected from a large pool of 110 patients treated with TACE. The treating radiologists were the same (GP and PF) for all patients, providing uniformity of treatment for both groups. A recent retrospective trial examined a population of 150 patients with liver cirrhosis treated between 2002 and 2009 that included 50 patients treated with TACE and 32 patients treated with DEB-TACE (24). For the entire population the median survival was 32 months, while the median time to progression was 24 months. However, it must stressed that OS was calculated as the time between the date of radiological or histological diagnosis of HCC and the date of death or last follow-up, while the RFS was calculated as the time between the date of treatment and the date of progression or last follow-up. In a recently published study, a survival benefit was reported with transcatheter DEB-TACE therapy over conventional TACE for patients with unresectable HCC Although we observed that RFS improved from 8.4 months for TACE to 13.1 months for DEB-TACE, the difference was not statistically significant; similarly, OS improved from 11.4 months for TACE to 18.4 months for DEB-TACE, but the difference was not statistically significant. The non-significant RFS and OS measurements in our study must be considered preliminary; further exploration will come after February 2012 after completion of the prospective randomized study NCT00539643 by Memorial Sloan-Kettering Cancer Center evaluating the role of doxorubicin added to DC Beads in HCC treatment.

Recently, the orally available multi-targeted receptor tyrosine kinase inhibitor sorafenib demonstrated a statistically significant improvement in median OS after 3 months versus the placebo in patients with advanced HCC (25). In another randomized study of Asian patients with advanced HCC, sorafenib treatment led to a net survival gain of 2.3 months versus placebo (26). In the future, an active area of investigation will be the combination of TACE with these multi-targeted receptor tyrosine kinase inhibitors.

\section{References}

1. Parkin DM, Bray F, Ferlay J and Pisani P: Global cancer statistics 2002. CA Cancer J Clin 55: 74-108, 2005.

2. El-Serag HB and Mason AC: Risk factors for the rising rates of primary liver cancer in the United States. Arch Intern Med 160: 3227-3230, 2000.

3. Rougier P, Mitry E, Barbare JC and Taieb J: Hepatocellular carcinoma (HCC): an update. Semin Oncol 34: S12-S20, 2007.

4. Hasegawa K, Makuuchi M, Takayama T, Kokudo N, Arii S, Okazaki M, Okita K, Omata M, Kudo M, Kojiro M, et al: Surgical resection vs. percutaneous ablation for hepatocellular carcinoma: a preliminary report of the Japanese nationwide survey. J Hepatol 49: 589-594, 2008

5. Lo CM, Ngan H, Tso WK, Liu CL, Lam CM, Poon RT, Fan ST and Wong J: Randomized controlled trial of transarterial lipiodol chemoembolization for unresectable hepatocellular carcinoma. Hepatology 35: 1164-1171, 2002.
6. Llovet JM, Real MI, Montaña X, Planas R, Coll S, Aponte J, Ayuso C, Sala M, Muchart J, Solà R, et al: Arterial embolisation or chemoembolisation versus symptomatic treatment in patients with unresectable hepatocellular carcinoma: a randomised controlled trial. Lancet 359: 1734-1739, 2002.

7. Shimamura $Y$, Gunvèn $P$, Takenaka $Y$, Shimizu $H$, Shima $Y$, Akimoto H, Arima K, Takahashi A, Kitaya T and Matsuyama T: Combined peripheral and central chemoembolization of liver tumors. Experience with lipiodol-doxorubicin and gelatin sponge (L-TAE). Cancer 61: 238-242, 1988.

8. Takayasu K, Suzuki M, Uesaka K, Muramatsu Y, Moriyama N, Yoshida T, Yoshino M, Okazaki N and Hasegawa H: Hepatic artery embolization for inoperable hepatocellular carcinoma: prognosis and risk factors. Cancer Chemother Pharmacol 23 (Suppl): S123-S125, 1989.

9. Yamada R, Sato M, Kawabata M, Nakatsuka H, Nakamura K and Takashima S: Hepatic artery embolization in 120 patients with unresectable hepatoma. Radiology 148: 397-401, 1983.

10. Takayasu K, Shima Y, Muramatsu Y, Moriyama N, Yamada T, Makuuchi M, Hasegawa H and Hirohashi S: Hepatocellular carcinoma: treatment with intraarterial iodized oil with and without chemotherapeutic agents. Radiology 163: 345-351, 1987.

11. Kawai S, Okamura J, Ogawa M, Ohashi Y, Tani M, Inoue J, Kawarada Y, Kusano M, Kubo Y and Kuroda C: Prospective and randomized clinical trial for the treatment of hepatocellular carcinoma - a comparison of lipiodol-transcatheter arterial embolization with and without adriamycin (first cooperative study). The Cooperative Study Group for Liver Cancer Treatment of Japan. Cancer Chemother Pharmacol 31 (Suppl): S1-S6, 1992.

12. Hong K, Khwaja A, Liapi E, Torbenson MS, Georgiades CS and Geschwind JF: New intra-arterial drug delivery system for the treatment of liver cancer: preclinical assessment in a rabbit model of liver cancer. Clin Cancer Res 12: 2563-2567, 2006.

13. Reyes DK, Vossen JA, Kamel IR, Azad NS, Wahlin TA, Torbenson MS, Choti MA and Geschwind JF: Single-center phase II trial of transarterial chemoembolization with drug-eluting beads for patients with unresectable hepatocellular carcinoma: initial experience in the United States. Cancer J 15: 526-532, 2009.

14. Okuda K, Ohtsuki T, Obata H, Tmmatsu M, Okazaki N, Hasegawa $\mathrm{H}$ and Nakajima Y: Natural history of hepatocellular carcinoma and prognosis in relation to treatment. Cancer 56: 918-928, 1985.

15. Kettenbach J, Stadler A, Katzler IV, Schernthaner R, Blum M, Lammer J and Rand T: Drug-looaded microdspheres for the treatment of liver cancer: review of current results. Cardiovasc Intervent Radiol 31: 468-476, 2008.

16. Therasse P, Arbuck SG, Eisenhauer EA, Wanders J, Kaplan RS, Rubinstein L, Verweij J, Van Glabbeke M, van Oosterom AT, Christian MC and Gwyther SG: New guidelines to evaluate the response to treatment in solid tumors. European Organization for Research and Treatment of Cancer, National Cancer Institute of the United States, National Cancer Institute of Canada. J Natl Cancer Inst 92: 205-216, 2000.

17. Kaplan EL and Meier P: Non-parametric estimation from incomplete observations. J Am Stat Assoc 53: 457-481, 1958.

18. Llovet JM, Real MI, Montaña X, Planas R, Coll S, Aponte J, Ayuso C, Sala M, Muchart J, Solà R, et al; Barcelona Liver Cancer Group. Barcelona Liver Cancer Group. Arterial embolisation or chemoembolisation versus symptomatic treatment in patients with unresectable hepatocellular carcinoma: a randomised controlled trial. Lancet 359: 1734-1739, 2002.

19. Lo CM, Ngan H, Tso WK, Liu CL, Lam CM, Poon RT, Fan ST and Wong J: Randomized controlled trial of transarterial lipiodol chemoembolization or unresectable hepatocellular carcinoma. Hepatology 35: 1164-1171, 2002.

20. Cammà C, Schepis F, Orlando A, Albanese M, Shahied L, Trevisani F, Andreone P, Craxì A and Cottone M: Transarterial chemoembolization for unresectable hepatocellular carcinoma: meta-analysis of randomized controlled trials. Radiology 224: 47-54, 2002.

21. van Malenstein H, Maleux G, Vandecaveye V, Heye S, Laleman W, van Pelt J, Vaninbroukx J, Nevens F and Verslype C: A randomized phase II study of drug-eluting beads versus transarterial chemoembolization for unresectable hepatocellular carcinoma. Onkologie 34: 368-376, 2011.

22. Poon RT, Fan ST, Lo CM, Liu CL and Wong J: Difference in tumor invasiveness in cirrhotic patients with hepatocellular carcinoma fulfilling the Milan criteria treated by resection and transplantation: impact on long-term survival. Ann Surg 245: 51-58, 2007. 
23. Malagari K, Pomoni M, Kelekis A, Pomoni A, Dourakis S, Spyridopoulos T, Moschouris H, Emmanouil E, Rizos S and Kelekis D: Prospective randomized comparison of chemoembolization with doxorubicin-eluting beads and bland embolization with BeadBlock for hepatocellular carcinoma. Cardiovasc Intervent Radiol 33: 541-551, 2010.

24. Scartozzi M, Baroni GS, Faloppi L, Paolo MD, Pierantoni C, Candelari R, Berardi R, Antognoli S, Mincarelli C, Risaliti A, et al: Trans-arterial chemo-embolization (TACE), with either lipiodol (traditional TACE) or drug-eluting microspheres (precision TACE, pTACE) in the treatment of hepatocellular carcinoma: efficacy and safety results from a large mono-institutional analysis. J Exp Clin Cancer Res 15: 164-171, 2010.
25. Llovet JM, Ricci S, Mazzaferro V, Hilgard P, Gane E, Blanc JF, de Oliveira AC, Santoro A, Raoul JL, Forner A, et al; SHARP Investigators Study Group: Sorafenib in advanced hepatocellular carcinoma. N Engl J Med 359: 378-390, 2008.

26. Cheng AL, Kang YK, Chen Z, Tsao CJ, Qin S, Kim JS, Luo R, Feng J, Ye S, Yang TS, et al: Efficacy and safety of sorafenib in patients in the Asia-Pacific region with advanced hepatocellular carcinoma: a phase III randomised, double-blind, placebocontrolled trial. Lancet Oncol 10: 25-34, 2009. 